\title{
Perencanaan Jaringan Komunikasi Backbone antara Bangka dan Belitung Menggunakan Radio Microwave SDH
}

\author{
Andri, Rianto Nugroho \\ Program Studi Teknik Elektro, Fakultas Teknik dan Sains, Universitas Nasional \\ Korespondensi : riantnugroho@yahoo.com
}

\begin{abstract}
ABSTRAK. Pembangunan jaringan telekomunikasi antara Pulau Bangka - Pulau Belitung menggunakan radio microwave dengan teknologi SDH (Synchronous Digital Hierarchy) yang dapat memenuhi kapasitas yang besar dan kehandalan yang cukup tinggi. Pemilihan komunikasi dengan radio microwave pada link ini disebabkan banyaknya kendala pada proses implementasinya, dimana link ini melewati lautan, oleh sebab itu tidak memungkinkan membangun komunikasi kabel laut dalam waktu relatif singkat. Maka sistem komuikasi radio microwave memberikan suatu solusi. Sistem ini merambat dalam garis pandang (line of sight) atau ruang bebas sehingga tidak diperlukan syarat utama yang harus dipenuhi dalam membangun komunikasi radio microwave. Sebelum membangun sistem komunikasi radio microwave maka dibutuhkan perencanaan agar sistem ini memenuhi kebutuhan suatu sistem komunikasi. Perencanaan dilakukan terdiri atas beberapa tahap seperti penentuan lokasi, penentuan rute radio link, konfigurasi radio link dan path analisys. Tahap-tahap tersebut dilaksanakan agar mendapatkan hasil yang maksimal pada suatu perencanaan. Hasil perencanaan dapat digunakan sebagai referensi penentuan penggunaan perangkat yang sesuai dengan spesifikasi dalam pembangunan komunikasi radio microwave dengan rute Pulau Bangka - Pulau Belitung agar mendapatkan hasil yang sesuai dengan standarisasi internasional. Dalam hal ini standar yang digunakan mengacu pada ITU-R.
\end{abstract}

Kata kunci: SDH (synchronous digital hierarchy), radio microwave, radio link

\begin{abstract}
Telecommunication network development between Bangka Island Belitung Island using radio microwave with SDH (Synchronous Digital Hierarchy) Technology can be the solution for the big capacity and high performance. Choosing communication using radio microwave for the link because a lot of constraint at process implementation, which one this link pass the ocean and then that impossible build cable on the ocean in the quick time and radio microwave become a solution for this issue. This system creeps at Line of Sight or Free Space Lost and so we no need physical line are like cable. LOS condition becomes the first condition if we want to build the microwave communication. Before building the system radio microwave communication we need planning, that is location determination, Radio Link route, Radio link configuration, and path analysis. That is the maximum result. The planning result can be used as a reference for equipment match with the specification, on the built communication, Radio microwave with route Bangka Island - Belitung Island getting result according to international standardization that is ITU-R.
\end{abstract}

Keywords: SDH (synchronous digital hierarchy), radio microwave, a radio link.

\section{PENDAHULUAN}

Kepulauan Bangka dan Belitung merupakan pulau yang terletak di bagian Selatan Pulau Sumatera. Kedua pulau tersebut dipisahkan oleh selat. Karena permintaan telekomunikasi pada area tersebut sangat tinggi maka diperlukan suatu sistem komunikasi yang dapat melewati perairan. Sistem komunikasi yang dipilih adalah menggunakan sistem komunikasi radio gelombang microwave dengan media transmisi udara. Sistem komunikasi radio gelombang microwave dipillih karena dapat melayani beberapa ribu saluran suara (voice) dengan tingkat kehandalan yang cukup tinggi serta jarak tempuh yang lebih efisien karena melewati media transmisi udara. 
Dalam perencanaan jaringan komunikasi ini akan disesuaikan dengan karakteristik Pulau Bangka dan Pulau Belitung.

\section{PARAMETER PENGUKURAN}

Sistem komunikasi dengan microwave sekarang beroperasi dengan modulasi QAM (Quadrature Amplitudo Modulation). Unjuk kerja dari komunikasi digital ini diukur dalam BER (Bite Error Rate). Level daya ambang batas untuk peralatan transceiver sering didefinisikan dimana BER (Bite Error Rate) mencapai $10^{-6}$ walupun nilai BER yang lain dapat diterima. Nilai tersebut menjadi parameter peralatan receiver. Microwave bekerja pada rentang Frekuensi $2 \mathrm{GHz}-23$ $\mathrm{GHz}$. Gelombang radio dari pemancar merambat menurut arah garis lurus. Ketika daya bergerak menjauhi sumber radiator isotropis, daya rata-rata $(P r)$ terpancar sama kesemua arah dan akan menyebar dalam bentuk bola, sehingga pada jarak $(d)$, kerapatan daya pada gelombang yang ada adalah daya persatuan luas permukaan gelombang yaitu ;

$$
P_{D i}=\frac{P_{r}}{4 \lambda \cdot d^{2}} \quad w / m^{2}
$$

dimana :

$P_{D i}:$ kecepatan daya isotropik

$\operatorname{Pr}$ : daya rata-rata

$d:$ jarak

Perolehan keterarahan (Directivity Gain) antena adalah perbandingan dari kerapatan daya yang sesungguhnya pada sumbu utama dari radiasi antena. Perolehan keterarahan maksimum (Gr) dari antena pemancar dan kerapatan daya di sepanjang arah dengan radiasi maksimum adalah :

$$
P_{D}=P_{D i} \cdot G_{T}=\frac{P_{r}}{4 \lambda \cdot d^{2}} G_{T}
$$

dimana :

$G_{T}$ : Perolehan keterarahan maksimum

\section{Koordinat Lokasi}

Koordinat lokasi dibutuhkan untuk menentukan beberapa parameter jarak antara dua titik, posisi, azimut dan kontur permukaan bumi yang akan dilalui oleh lintasan gelombang radio. Dengan bantuan peta berskala yang dilengkapi dengan garis-garis koordinat dan garis kontur permukaan bumi. Koordinat lokasi diperoleh dengan menentukan titik pada kontur bumi berupa posisi titik tersebut pada garis Lintang dan garis Bujur.

\section{Path Profile}

Path profile (Peta Penampang) dengan metode flat earth curve adalah alat bantu berupa grafik berskala yang dipergunakan untuk menentukan kondisi lintasan memenuhi syarat LOS atau tidak $L O S$ dengan proyeksi permukaan bumi datar. Parameter yang harus diperhatikan dalam penggambarannya adalah daerah fresnell, tinggi obstacle sepanjang lintasan, koreksi ketinggian tiap obstacle di sepanjang lintasan, high clearence dan jarak.

\section{Daerah Fresnell}

Daerah fresnell adalah tempat kedudukan titik-titik sinyal tak langsung (berbentuk ellips) dalam lintasan gelombang radio, dimana daerah tersebut dibatasi oleh gelombang tak langsung yang mempunyai beda panjang lintasan dengan sinyal langsung, seperti rumus dibawah ini :

$$
F 1=17,3 \sqrt{\frac{d 1 . d 2}{f . d} m}
$$


dimana :
$f$ : frekuensi $(\mathrm{GHz})$
$d:$ jarak lintasan $(K m)$
$d_{1} \& d_{2}:$ jarak $(\mathrm{Km})$ dari terminal kelintasan obstacle

\section{Koreksi Ketinggian}

Apabila koreksi ketinggian diperlukan karena penggambaran terhadap kondisi bumi yang terbentuk bulat, hal ini memberikan pengaruh terhadap tinggi obstacle pada sepanjang lintasan sistem telekomunikasi gelombang radio mikro, seperti persamaan dibawah ini :

$$
h_{k}=\frac{d_{1} \cdot d_{2}}{12,75 \times \mathrm{K}} m
$$

dimana :

$h_{\mathrm{k}}$ : koreksi ketinggian $(m)$ terhadap permukaan laut

$\mathrm{K}$ : faktor kelengkungan bumi (konstanta)

$d_{1} \& d_{2}:$ jarak $(\mathrm{Km})$ dari terminal ke lintasan obstacle

\section{High Clerence}

High clerence adalah jarak antara sumbu utama lintasan gelombang radio dengan puncak penghalang (obstacle). Agar syarat Line Of Sight (LOS) terpenuhi maka besarnya tinggi obstacle harus dperhitungkan pada titik dimana terletak obstacle yang tertinggi, yaitu :

$$
h_{c}=\frac{h_{1} \cdot d_{2}+h_{2} \cdot d_{1}}{d}-h_{k-} h_{s}
$$

dimana :

$h_{c}$ : ketinggian obstacle $(\mathrm{m})$ terhadap permukaan laut

$h_{l}$ : ketinggian antena $1(m)$ terhadap permukaan laut

$h_{2}$ : ketinggian antena $2(m)$ terhadap permukaan laut

$h_{k}$ : koreksi ketinggian $(m)$ terhadap permukaan laut

$h_{s}$ : ketinggian obstacle $(m)$ terhadap permukaan laut

$d 1 \& d 2:$ jarak $(\mathrm{Km})$ dari terminal ke lintasan obstacle

\section{Power Link Budget}

Level daya terima nominal (Receive Signal Level) sistem transmisi dapat dihitung dengan persamaan berikut :

$$
R S L=P_{\mathrm{t}}+\mathrm{G}_{\text {total }}+L_{\text {trasmisi }}
$$

dimana :

$R S L$ : level daya terima $(\mathrm{dBm})$

$P_{\mathrm{t}}$ : Daya Transmisi $(\mathrm{dBm})$

$\mathrm{G}_{\text {total }}$ : Gain Total Antena Rx dan Tx $(d B)$

$\mathrm{L}_{\text {tra }}:$ Redaman Transmisi $(d B)$

\section{Fading}

Fading adalah variasi sinyal terima saat sebagai fungsi dari fasa, polarisasi dan kuatnya sinyal terima akibat pengaruh hambatan lintasan baik itu pembiasan, pemantulan, difraksi, hamburan, redaman dan karena akibat-akibat yang lain. Flat Fading mempunyai karakteristik dimana level sinyal naik turun dengan lambat, hal ini menyebabkan putusnya hubungan yang lama. Flat fading terjadi akibat pembelokan beam yang di sebabkan oleh perubahan indeks bias atmosfer. Pada kondisi standar faktor $K=4 / 3$.Sementara Frequency Selective Fading dimana kondisi super refraksi K> 4/3 menyebabkan beam membelok ke bawah. Pembelokan ini akan menyebabkan gelombang akan terpantul oleh permukaan bumi, sehingga akan membentuk lintasan lain selain lintasan gelombang langsung. Sedangakan Fading Margin adalah perbedaan antara level sinyal terima nominal dengan level sinyal terima minimum (threshold), yang sesuai 
dengan bit error rate (BER) yang diinginkan. Flat Fading Margin (FFM) dihitung untuk mengatasi error yang disebabkan thermal noise.

Dihitung dengan rumus sebagai berikut :

$$
F F M=R S L-R x_{(\text {threshold })}
$$

dimana : FFM : Flat Fading Margin

$R S$ : level daya terima $(\mathrm{dBm})$

$R x_{(h r e s h o l d)}$ : level threshold dari thermal noise penerima $(\mathrm{dBm})$

\section{Probabilitas Outage}

Probabilitas outage adalah kemungkinan putusnya suatu hubungan komunikasi. Probabilitas outage perlu diperhitungkan dalam perancangan sistem gelombang mikro karena diperlukan untuk mengestimasi kondisi terburuk atau dalam kondisi fading terburuk agar komunikasi tidak terputus. Pada transmisi gelombang mikro, outage disebabkan oleh distorsi gelombang akibat Frequency Selective Fading, interferensi dan noise thermal. Rekomendasi ITU-R 633-3 menetapkan propagasi outage dengan panjang lintasan $2500 \mathrm{Km}$ dan maksimum 9 hop, untuk $280 \leq L \leq 2500 \mathrm{Km}$ :

$P_{t} \leq(280 / 2500) \times 0.4 \%$

$P_{t} \leq 0,000448$

Availability sistem radio diatur oleh rekomendasi ITU-R F634-3, dimana untuk sistem radio dengan panjang lintasan $\leq 280 \mathrm{Km}$ adalah:

$A V \geq\left(100-\mathrm{P}_{\mathrm{o}}\right) \%$

$A V \geq(1-0,00448)$

$A V \geq 0,999252$

\section{Probabilitas Outage untuk Sistem Tanpa Menggunakan Teknik Diversity}

Berdasarkan rekomendasi ITU-R P.530-8 untuk menghitung probabilitas outage total sistem adalah sebagai berikut:

$P t=P_{n s}+P_{s}+P_{x p}$

dimana :

$P_{n s} \quad$ : probabilitas outage disebabkan non-selective fading

$P_{s} \quad$ : probabilitas outage disebabkan selective fading

$P_{x p} \quad$ : probabilitas outage disebabkan $x p$ degradasi

\section{Probabilitas Outage untuk Sistem Menggunakan Teknik Diversitas}

Teknik diversitas adalah suatu teknik dimana memiliki penerimaan rangkap. Adapun teknik yang digunakan adalah teknik space diversity. Penggunaannya saat kasus radio link memiliki jarak yang jauh dan untuk menghindari multipath fading. Harga total probabilitas outage menggunakan teknik diversitas dihitung dengan persamaan :

$$
P_{t}=P_{d} x P_{x p}
$$

dimana :

$P_{d}$ : kombinasi probabilitas outage disebabkan oleh selective dan non selective

\section{PERENCANAAN JARINGAN TRANSMISI}

\section{Penentuan Lokasi dan Route Radio Link}

Peta rute dibuat untuk melihat jalur yang akan digunakan untuk jaringan radio microwave dan juga melihat kondisi geografisnya secara umum. Lokasi yang akan dijadikan stasiun berjumlah 5 Site. 


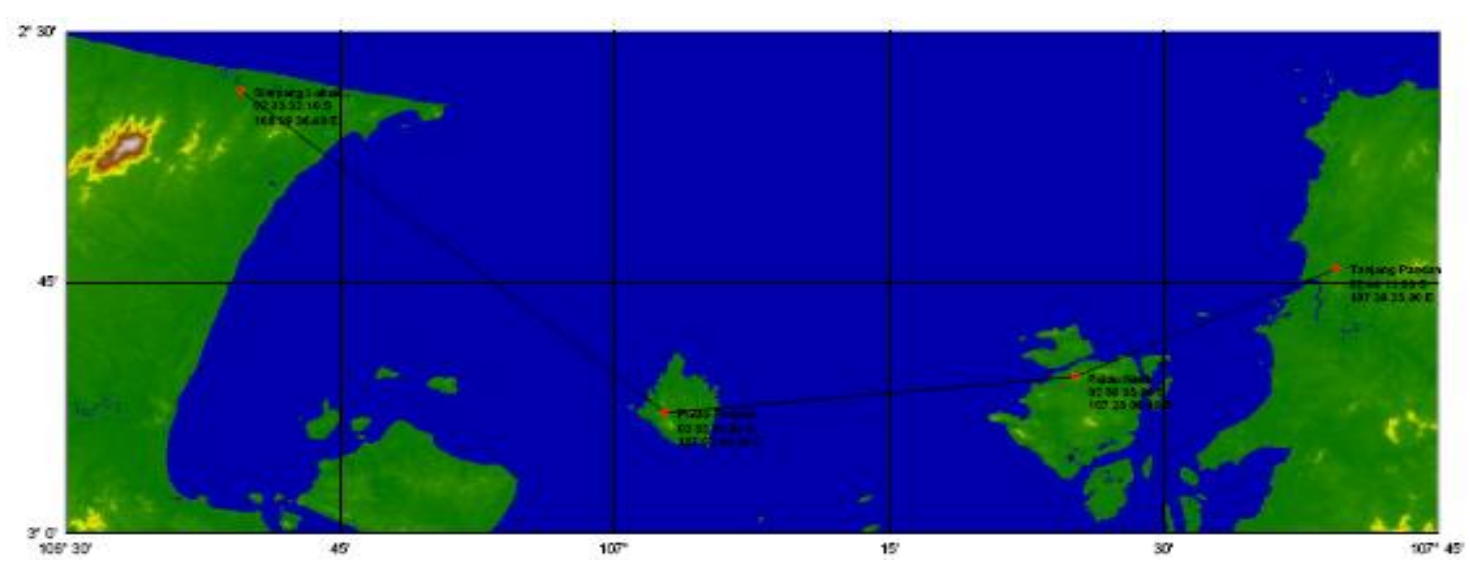

GAMBAR Peta geografi lokasi pemasangan jaringan Radio Link.

TABEL Data geografi lokasi pemasangan Radio Link

\begin{tabular}{|c|l|c|c|c|}
\hline No. & \multicolumn{1}{|c|}{ Nama Site } & Longitude & Lattitude & Elevasi (mASL) \\
\hline 1. & Simpang Lubuk & $02^{\circ} 33^{\prime} 32.10^{\prime \prime} \mathrm{S}$ & $106^{\circ} 39^{\prime} 36.40^{\prime \prime} \mathrm{E}$ & 11 \\
\hline 2. & Pulau Pongok & $02^{\circ} 52^{\prime} 45.99^{\prime \prime} \mathrm{S}$ & $107^{\circ} 02^{\prime} 45.00^{\prime} \mathrm{E}$ & 67 \\
\hline 3. & Pulau Nasik & $02^{\circ} 50^{\prime} 35.90^{\prime \prime} \mathrm{S}$ & $107^{\circ} 25^{\prime} 09.40{ }^{\prime} \mathrm{E}$ & 69 \\
\hline 4. & Tanjung Pandan & $02^{\circ} 44^{\prime} 11.00^{\prime} \mathrm{S}$ & $107^{\circ} 39^{\prime} 25.00^{\prime \prime} \mathrm{E}$ & 25 \\
\hline
\end{tabular}

TABEL Data Jarak antar Link

\begin{tabular}{|c|l|l|c|c|}
\hline No. & \multicolumn{1}{|c|}{ Site A } & \multicolumn{1}{|c|}{ Site B } & Jarak $(\mathrm{Km})$ & Keterangan \\
\hline 1. & Simpang Lubuk & Pulau Pongok & 55.85 & LOS \\
\hline 2. & Pulau Pongok & Pulau Nasik & 41.71 & LOS \\
\hline 3. & Pulau Nasik & Tanjung Pandan & 28.95 & LOS \\
\hline
\end{tabular}

\section{Path Profile Radio Link}

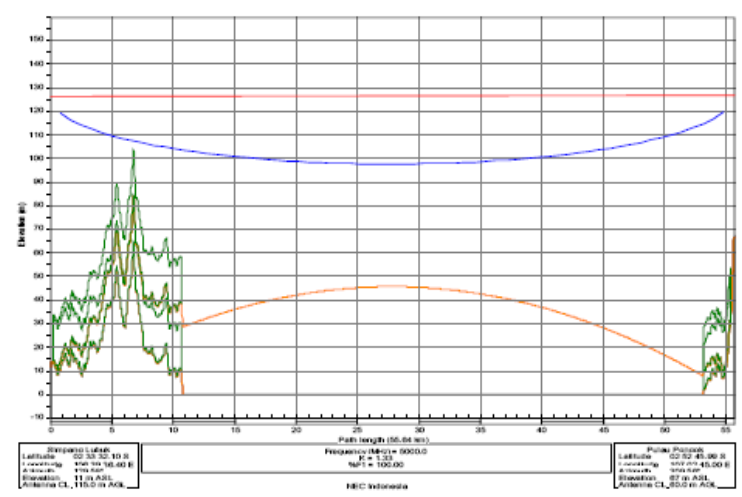

GAMBAR Path Profile Radio Link Simpang Lubuk - Pulau Pongok

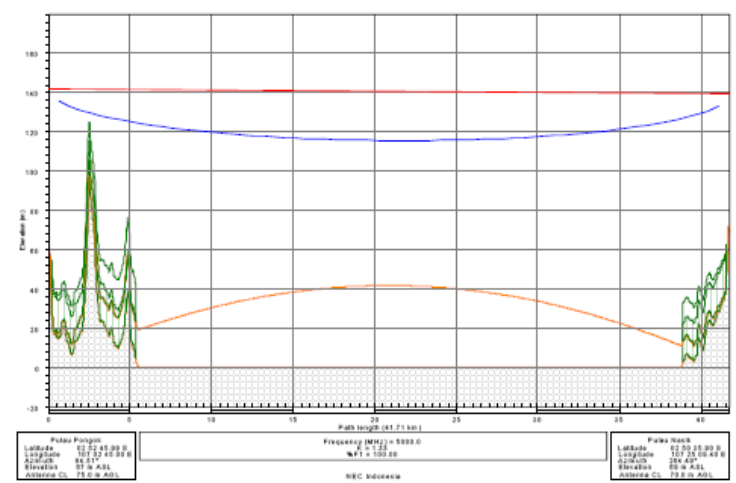

GAMBAR Path Profile Radio Link Pulau Pongok - Pulau Nasik 


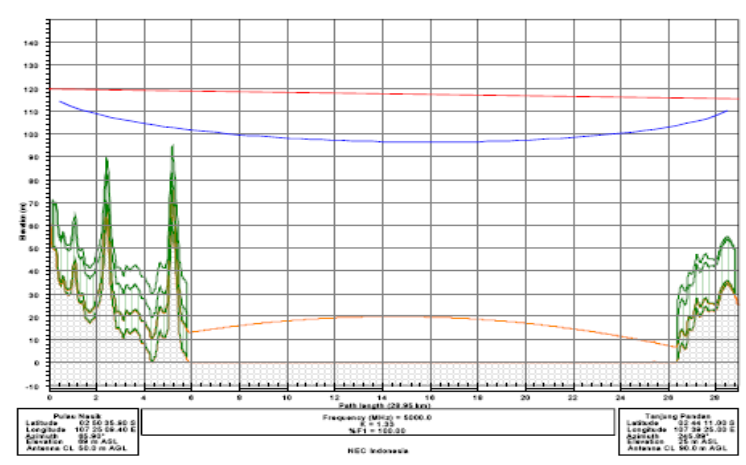

GAMBAR Path Profile Radio Link Pulau Nasik - Tanjung Pandan

\section{Konfigurasi Radio Link}

Pada SDH (Synchronous Digital Hierarcy) adalah teknologi yang memiliki sinkronisasi clock dan kapasitas yang tinggi. Pada perencanaan ini di asumsikan kebutuhan akan kapasitas kanal besar 6 x STM-1 (155 Mbps), maka radio yang akan digunakan teknologi SDH STM-1. Sedangkan frekuensi kerja yang digunakan adalah $5 \mathrm{GHz}$.

\section{ANALISA PERENCANAAN PADA RADIO LINK}

Berdasarkan data yang diperoleh akan dihitung secara teoritis perencanaan radio link dengan menggunakan microwave yang kemudian akan dianalisa hasil perencanaan jaringan transmisi tersebut. Adapun link yang akan dianalisa hanya diambil salah satu link saja, mengingat cara penghitungan link-link yang lain adalah sama sebagai berikut :

- Simpang Lubuk - Pulau Pongok

- Pulau Pongok - Pulau Nasik

- Pulau Nasik - Tanjung Pandan

Analisa perencanaan radio link yang telah disebutkan diatas mencakup beberapa hal sebagai berikut :

- Pembuatan Path Profile:

a. Perhitungan Jari-Jari Fresnell 1

b. Perhitungan Koreksi Ketinggian

c. Perhitungan High Clearence

- Perhitungan Power Link Budget:

a. Perhitungan Redaman

b. Perhitungan Level Daya Terima (RSL)

c. Perhitungan Flat Fade Margin

- Perhitungan Probabilitas Outage Tanpa Menggunakan Teknik Diversitas :

a. Perhitungan Probabilitas Non-Selective Outage

b. Perhitungan Probabilitas Selective Outage

- Perhitungan Probabilitas Outage Dengan Menggunakan Teknik Diversitas

\section{Analisa Radio Link Simpang Lubuk - Pulau Pongok \\ Perhitungan Jari-jari Fresnell 1}

Perhitungan jari-jari fresnell 1 dapat dihitung pada lintasan gelombang radio yang melalui obstacle tertinggi sesuai dengan jarak $7 \mathrm{Km}(d l)$ dari Simpang Lubuk dan dari obstacle tertinggi ke Pulau Pongok $55 \mathrm{Km}(d 2)$ dengan persamaan sbb :

$$
\begin{aligned}
& F_{1}=17,3 \sqrt{\frac{d 1 . d 2}{f . d} m} \\
& F_{1}=17,3 \sqrt{\frac{7 x 48,85}{5 \times 55,85} m} \\
& F_{1}=19,14 \mathrm{~m}
\end{aligned}
$$




\section{Perhitungan Koreksi Ketinggian}

Faktor koreksi terhadap kelengkungan bumi pada titik obstacle tertinggi sesuai dengan persamaan :

$$
\begin{aligned}
h_{k} & =\frac{d_{1} \cdot d_{2}}{12,75 \times \mathrm{K}} m \\
h_{k} & =\frac{7 \times 48,85}{12,75 \times 1.33} m \\
h_{k} & =20,165 \mathrm{~m}
\end{aligned}
$$

\section{Perhitungan High Clearence}

Kondisi lintasan dalam link Simpang Lubuk - Pulau Pongok merupakan kontur perbukit dan laut dengan perkiraan ketinggian pepohonan 20 meter sehingga tinggi obstacle bertambah 20 meter. Maka high clearence di peroleh dengan persamaan sebagai berikut :

$$
\begin{aligned}
& h_{c}=\frac{h_{1} \cdot d_{2}+h_{2} \cdot d_{1}}{d}-h_{k-} h_{s} \\
& h_{c}=\frac{115 \times 48,85+60 \times 7}{55,85}-20,165-65 \\
& h_{c}=22,941 \mathrm{~m}
\end{aligned}
$$

\section{Perhitungan Power Link Budget}

\section{Perhitungan Redaman Transmisi}

Besarnya redaman transmisi pada suatu lintasan sesuai dengan persamaan sebagai berikut :

$L_{\text {tra }}=F S L+L_{b}+L f+L_{\text {rain }}+L_{a t m}+L_{o}$

- Perhitungan Redaman Ruang Bebas (FSL), redaman ruang bebas diperoleh dengan persamaan :

$F S L=32,44+20 \log f(\mathrm{MHz})+20 \log d(\mathrm{Km})$

$F S L=32,44+20 \log 5000(\mathrm{MHz})+20 \log 55,85(\mathrm{~km})$

$F S L=32,44+73,98+34,94$

$F S L=141,36 \mathrm{~dB}$

- Readaman Brancing Circuit (Lb) diasumsikan $1 \mathrm{~dB}$

- Redaman feeder (Lf) diasumsikan (3dB/100)

- Perhitungan redaman atmosfer $\left(L_{a t m}\right)$

$L_{\text {atm }}=I \alpha \times \mathrm{d} \mathrm{dB}$

$L_{\text {atm }}=0,0524 \times 55,85 \mathrm{~dB}$

$L_{\text {atm }}=2,92 \mathrm{~dB}$

- Perhitungan Redaman Hujan $\left(L_{\text {rain }}\right)$

Pada perhitungan redaman hujan agar dapat mengantisipasi keadaan terburuk diasumsikan antena berpolarisasi horizontal karena memberikan redaman maksimal dan hujan terjadi di sepanjang lintasan. Berdasarkan rekomendasi ITU-R P.8372 Indonesia termasuk ke dalam zona $\mathrm{P}$ dengan curah hujan $145 \mathrm{~mm} / \mathrm{h}$ :

dimana :

$$
\begin{aligned}
& L_{\mathrm{rain}}=I R d_{e f f} \mathrm{~dB} \\
& I R=K \times R^{\alpha} \\
& d_{\text {eff }}=d \cdot r \\
& r=\frac{1}{1+d / d o}
\end{aligned}
$$

$K:$ Faktor iklim

$R$ : Curah hujan 
$\alpha: 1.332$

$\mathrm{d}_{0}: 7.810$

Berdasarkan rekomendasi ITU-R P.530-8, nilai $C_{o}=3.5 ; C_{\text {lat }}=0 ; C_{\text {ion }}=0 \mathrm{~dB}$. Untuk nilai $P_{L}$ dapat direkomendasikan ITU-R P.353 maka didapat $P_{L}=20 \%$. Perhitungan geoclimatic factor berdasarkan letak radio link yang termasuk dalam kategori coastal link with large size bodies of water sehingga di dapat perhitungan sebagai berikut :

$$
K_{i}=5.0 \times 10^{-7} \times 10^{0.1\left(C_{o}-C_{l a t}-C_{L o n}\right)} P_{L}^{1.5}
$$

dimana :

$$
\begin{aligned}
& P_{L} \text { : variabel iklim (\%) } \\
& C_{o} ; \mathrm{C}_{\text {lat }} ; \mathrm{C}_{\mathrm{Lon}}: \text { tetapan }(d B) \\
& K_{i}=5.0 \times 10^{-7} \times 10^{0.1(3.5-0-0)} \times 20^{1.5} \\
& K_{i}=0.000019976 \\
& K_{c l}=2,3 \times 10^{-4} \times 10^{0,1 C o-0,01[\xi]}, \xi=0 \\
& K_{c l}=2,3 \times 10^{-4} \times 10^{0,1(3.5-0,0110]} \\
& K_{c l}=2,3 \times 10^{-4} \times 10^{0,1 C o-0,01[\xi]} \\
& K_{c l}=0.0005149059 \\
& K=10^{(1-r c) \log K i+r c \log K_{c l}} \\
& K=10^{(1-0.9) \log 0.0000199760 .9 \log 0.000514905 !} \\
& K=0.000372 \\
& I R=K x R^{\alpha} \\
& I R=0.000372 \times 1451.332 \\
& I R=0.281546 \mathrm{~dB} / \mathrm{Km} \\
& r=\frac{1}{1+d / d o} \\
& r=\frac{1}{1+55,85 / 7.810} \\
& r=0.1373779 \\
& d_{\text {eff }}=d . r \\
& d_{\text {eff }}=7,67 \mathrm{Km} \\
& L_{\text {rain }}=I R \times d_{\text {eff }} \\
& L_{\text {rain }}=0,281546 \times 7,67 d B \\
& L_{\text {rain }}=2,15945782 d B
\end{aligned}
$$

Maka akan diperoleh redaman transmisi yaitu :

$$
\begin{aligned}
& L_{\text {trasmisi }}=F S L+L_{b}+L f+L_{\text {rain }}+L_{\text {atm }}+L_{o} \\
& \text { dimana }: L_{o \text { diasumsikan } 0} \\
& L_{\text {trasmisi }}=141,36+1+(3 / 100)+2,92 \\
& L_{\text {trasmisi }}=144,31 d B
\end{aligned}
$$

- Perhitungan Gain Antena

Diameter antena yang digunakan pada link ini adalah 4,6 meter

$$
\begin{aligned}
& G=10 \log \left[\frac{(\lambda d)^{2} P}{\lambda^{2}}\right] d B \\
& \mathrm{G}=44,62 d B
\end{aligned}
$$

dimana :

$d:$ Diameter antena $(\mathrm{m})$

$P$ : Efesiensi antena dalam prosentase, nilai khas antara $0.4-0.8$ 


\section{$\lambda$ : Panjang gelombang $(\mathrm{m})$}

Gain total dari penjumlahan gain pada antena dan gain pada perangkat. Data dari perangkat di peroleh penguatan (gain) sebesar $33 \mathrm{dBm}$. Maka diperoleh gain totalnya adalah :

$$
\begin{aligned}
& G_{\text {total }}=G_{A T X}+G_{A R X}+G_{T X} \\
& G_{\text {total }}=44,62 \mathrm{dbi}+44,62 \mathrm{dbi}+45 \mathrm{dBm} \\
& G_{\text {total }}=134,24 \mathrm{dBm}
\end{aligned}
$$

Perhitungan Receiving Signal Level (RSL)

Level sinyal yang di terima, di peroleh dari penguatan total (gain total) dengan redaman transmisi. Maka di peroleh level sinyal yang di terima adalah sebagai berikut :

$$
\begin{aligned}
& R S L=\mathrm{G}_{\text {total }}-L_{\text {trasmisi }} \\
& R S L=134,24 \mathrm{dBm}-144,31 \mathrm{~dB} \\
& R S L=-10,07 \mathrm{dBm}
\end{aligned}
$$

\section{Perhitungan Flat Fading Margin (FFM)}

Flat Fading Margin di peroleh dari pengurangan RSL dengan level ambang terima ( $\left.R x_{\text {threshold }}\right)$. Dari daftar tabel diperoleh $R x_{\text {threshold }}$ sebesar-74.60 dBm, sehingga Flat Fading Margin sebesar :

$$
F F M=R S L-R x_{(\text {threshold })}
$$

dimana :

FFM : Flat Fading Margin

$R S L \quad$ : Level daya terima $(\mathrm{dBm})$

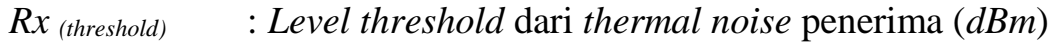

$$
\begin{aligned}
& F F M=-10,07 \mathrm{dBm}-(-74,60 \mathrm{dBm}) \\
& F F M=64,53 \mathrm{~dB}
\end{aligned}
$$

\section{Perhitungan Probabilitas Outage Tanpa Menggunakan Teknik Diversitas}

Kemampuan operasional sistem transmisi dalam menyalurkan informasi di ukur dalam dua parameter, yaitu Probabilitas total outage dan Availability.Probabilitas total outage $\left(P_{t}\right)$ pada $\mathrm{BER}=10^{-6}$ yang telah ditetapkan oleh rekomendasi ITU-R F.634-3 untuk sistem radio dengan panjang lintasan $\mathrm{L} \leq 280 \mathrm{Km}$ adalah :

$$
\begin{aligned}
& P_{t} \leq(280 / 2500) \times 0.4 \% \\
& P_{t} \leq 0,0448 \% \\
& P_{t} \leq 0,000448
\end{aligned}
$$

Availability sistem radio di atur oleh rekomendasi ITU-R F.634-3, dimana untuk sistem radio dengan panjang lintasan $\mathrm{L} \leq 280 \mathrm{Km}$ adalah :

$$
\begin{aligned}
& A V \geq\left(100-\mathrm{P}_{\mathrm{o}}\right) \% \\
& A V \geq(1-0,00448) \\
& A V \geq 0,999252
\end{aligned}
$$

\section{- Perhitungan Geoclimatic Factor}

Berdasarkan rekomendasi ITU-R P.530-8, nilai $C_{o}=3.5 ; C_{l a t}=0 ; C_{i o n}=0 d B$. Untuk nilai $P_{L}$ dapat direkomendasikan ITU-R P.353 maka didapat $P_{L}=20 \%$.Perhitungan geoclimaticfactor berdasarkan letak radio link yang termasuk dalam kategori coastal link with large size bodies of water sehingga di dapat perhitungan sebagai berikut:

$$
K_{i}=5.0 \times 10^{-7} \times 10^{0.1\left(C_{o}-C_{\text {lat }}-C_{\text {Lon }}\right)} P_{L}^{1.5}
$$

dimana :

$$
\begin{aligned}
& P_{L}: \text { variabel } \mathrm{iklim}(\%) \\
& C_{o} ; \mathrm{C}_{\text {lat }} ; \mathrm{C}_{\text {Lon }}: \text { tetapan }(d B) \\
& K_{i}=5.0 \times 10^{-7} \times 10^{0.1(3.5-0-0)} 20^{1.5} \\
& K_{i}=0.000019976 \\
& K_{c l}=2,3 \times 10^{-4} \times 10^{0,1 C o-0,01 \llbracket \xi]}
\end{aligned}
$$




$$
\begin{aligned}
& K_{c l}=2,3 \times 10^{-4} \times 10^{0,1(3.5-0,01 \llbracket 0]} \\
& K_{c l}=0.0005149059 \\
& K=10^{(1-r c) \log K i+r c \log K_{c l}} \\
& K=0.000372054
\end{aligned}
$$

- Perhitungan Magnitudo Kemiringan Lintasan

$$
|\varepsilon p|=\frac{\left|h_{r}-h_{e}\right|}{d} \operatorname{mrad}
$$

dimana :

$h_{r} ; h_{e} \quad$ : Tinggi antena terhadap permukaan laut $(m)$

$d$ : Jarak radio link $(\mathrm{Km})$

$$
\begin{aligned}
& |\varepsilon p|=\frac{|126-127|}{55,85} \mathrm{mrad} \\
& |\varepsilon p|=0,0179 \mathrm{mrad}
\end{aligned}
$$

- Perhitungan $P_{W}$

$$
P w=K x d^{3.6} x f^{0.89} x(1+|\varepsilon p|)^{-1.4} \times 10^{-A / 10}
$$

dimana :

$d:$ Jarak radio link $(\mathrm{Km})$

$f$ : Frekuensi $(G h z)$

$K$ : Faktor iklim dan efek terrain

$\varepsilon p$ : Magnitudo dari kemiringan lintasan

A : Flat fading margin $(d B)$

$$
\begin{aligned}
& P w=0,000372 \times 55,85^{3.6} \times 5^{0.89} \times(1+\mid 0,0179)^{-1.4} \times 10^{-64,53 / 10} \\
& P w=0,0010426 \%
\end{aligned}
$$

\section{Perhitungan Probabilitas Outage Non-Selective}

$$
\begin{aligned}
& P_{n s}=\frac{P w}{100} \\
& P_{n s}=\frac{0,00012780}{100} \\
& P_{n s}=0,00001278
\end{aligned}
$$

- Perhitungan Multipath Occurance

$$
\begin{aligned}
& P_{0}=\frac{P w}{100} \text { dengan } A=0(\%) . \\
& P_{0}=\frac{0.000372 \times 55,85^{3.6} \times 5^{0.89} \times(1+|0,0179|)^{-1.4} \times 10^{0 / 10}}{100} \\
& P_{0}=29,5888
\end{aligned}
$$

- Perhitungan Multipath Activity

$$
\begin{aligned}
& \eta=1-\exp \left(-0.2 x p_{o}{ }^{0,75}\right) \\
& \eta=1-\exp \left(-0.2 x 29.58^{0,75}\right) \\
& \eta=0.9209
\end{aligned}
$$

- Perhitungan Mean Time Delay 


$$
\begin{aligned}
\tau_{m} & =0.7\left(\frac{d}{50}\right)^{1,3} \\
\tau_{m} & =0.7\left(\frac{55,85}{50}\right)^{1,3} \\
\tau_{m} & =0.80828 n s
\end{aligned}
$$

\section{Perhitungan Probabilitas Outage Selective}

$$
P s=2,15 \eta\left(W_{m} x 10^{-B m / 20} x \frac{\tau_{m}{ }^{2}}{\tau_{r} M}+W_{M N} x 10^{-B M N / 20} x \frac{\tau_{m}{ }^{2}}{\tau_{r} M N}\right)
$$

dimana :

$\eta=0.9209 ; \tau_{m}=0,80828 n s ; \mathrm{W}_{\mathrm{M}}=0.024 \mathrm{GHz} ; \mathrm{W}_{\mathrm{MN}}=0.024 \mathrm{GHz} ; \mathrm{B}_{\mathrm{M}}=32 ;$

$\mathrm{B}_{\mathrm{MN}}=25 ; \tau_{r}, \mathrm{M}=\tau_{r}, \mathrm{MN}=6.3$;

dimana :

$\eta$ : parameter multipath activity

$W_{m}$ : minimum phase signature width

$W_{M N}$ : non minimum phase signature width

$B_{M}:$ minimum pahse notch depth

$B_{M N}:$ non minimum pahse notch depth

$\tau_{r}:$ reference time delay of signature curve

$\tau_{m}:$ mean time delay

$$
\begin{aligned}
& P s=2,15(0,9209)\left(0,024 \times 10^{-32 / 20} \times \frac{2,333872^{2}}{6,3}+0,24 \times 10^{-25 / 20} \times \frac{2,333872^{2}}{6,3}\right) \\
& P s=0,0027896
\end{aligned}
$$

- Perhitungan Probabilitas Outage Total

$$
\begin{aligned}
& P_{t}=P_{n s}+P_{s} \\
& P_{t}=0,000010426+0,0027896 \\
& P_{t}=0,00280026
\end{aligned}
$$

- Perhitungan Availability

$$
\begin{aligned}
& A v=1-P t \\
& A v=1-0,00280026 \\
& A v=0,99719974
\end{aligned}
$$

Perhitungan Probabilitas Outage Menggunakan Teknik Space Diversitas

Probabilitas total outage $\left(P_{t}\right)$ pada BER $=10^{-6}$ yang telah ditetapkan oleh rekomendasi ITU-R F.634-3 untuk sistem radio dengan panjang lintasan $\mathrm{L} \leq 280 \mathrm{Km}$ adalah :

$$
\begin{aligned}
& P t \leq(280 / 2500) \times 0.4 \% \\
& P t \leq 0,0448 \% \\
& P t \leq 0,000448
\end{aligned}
$$

Availability sistem radio di atur oleh rekomendasi ITU-R F.634-3, dimana untuk sistem radio dengan panjang lintasan $\mathrm{L} \leq 280 \mathrm{Km}$ adalah :

$$
\begin{aligned}
& A V \geq(100-\mathrm{Po}) \% \\
& A V \geq(1-0,00448) \\
& A V \geq 0,999252 \\
& P t=P n s+P_{s}
\end{aligned}
$$

- Perhitungan Probabilitas Outage Dengan Teknik Space Diversity

$$
I_{n s}=\left\lfloor 1-\exp \left(-3,34 \times 10^{-4} S^{0,87} f^{-0,12} d^{0,48} P_{o}^{-1,04}\right)\right\rfloor \times 10^{(A-V) / 10}
$$




$$
\begin{aligned}
& V=\left|G_{1}-G_{2}\right| \\
& V=0 \\
& P_{0}=\frac{P w x 10^{A / 10}}{100} \\
& P w=K x d^{3.6} \times f^{0.89} \times(1+|\varepsilon p|)^{-1.4} \times 10^{-A / 10}
\end{aligned}
$$

- Perhitungan Geoclimatic Factor

Berdasarkan rekomendasi ITU-R P.530-8, nilai $C_{o}=3.5 ; C_{l a t}=0 ; C_{i o n}=0 \mathrm{~dB}$. Untuk nilai $P_{L}$ dapat direkomendasikan ITU-R P.353 maka didapat $P_{L}=20 \%$

$$
K_{i}=5.0 \times 10^{-7} \times 10^{0.1\left(C_{o}-C_{\text {lat }}-C_{\text {Lon }}\right)} P_{L}^{1.5}
$$

dimana :

$$
\begin{aligned}
& P_{L}: \text { variabel iklim }(\%) \\
& C_{o} ; \mathrm{C}_{\text {lat }} ; \mathrm{C}_{\text {Lon }}: \text { tetapan }(d B) \\
& K_{i}=5.0 \times 10^{-7} \times 10^{0.1(3.5-0-0)} 20^{1.5} \\
& K_{i}=0.000019976 \\
& K_{c l}=2,3 \times 10^{-4} \times 10^{0,1 C o-0,01 \llbracket \xi]}, \xi \text { (latitude) }=0 \\
& K_{c l}=2,3 \times 10^{-4} \times 10^{0,1(3.5-0,01[0]} \\
& K_{c l}=0.0005149059 \\
& K=10^{(1-r c) \log K i+r c \log K_{c l}} \\
& K=0.000372054
\end{aligned}
$$

- Perhitungan Magnitudo Kemiringan Lintasan

$$
|\varepsilon p|=\frac{\left|h_{r}-h_{e}\right|}{d} \mathrm{mrad}
$$

dimana :

$h_{r} ; h_{e}$ : tinggi antena terhadap permukaan laut $(m)$

$d:$ jarak radio link $(\mathrm{Km})$

$$
\begin{aligned}
& |\varepsilon p|=\frac{126-127}{55,85} \mathrm{mrad} \\
& |\varepsilon p|=0,0179 \mathrm{mrad}
\end{aligned}
$$

- Perhitungan $P_{W}$

$$
\begin{aligned}
& P w=K x d^{3.6} \times f^{0.89} x(1+|\varepsilon p|)^{-1.4} \times 10^{-A / 10} \\
& P w=0,0010426 \%
\end{aligned}
$$

- Perhitungan Multipath Occurance

$$
\begin{aligned}
& P_{0}=\frac{P w \times 10^{A / 10}}{100} . \\
& P_{0}=29,588
\end{aligned} .
$$

- Perhitungan Multipath Activity

$$
\begin{aligned}
& \eta=1-\exp \left(-0,2 x p_{o}^{0,75}\right) \\
& \eta=0,921
\end{aligned}
$$

- Perhitungan Improvement Factor 
dimana :

$$
I_{n s}=\left\lfloor 1-\exp \left(-3,34 \times 10^{-4} S^{0,87} f^{-0,12} d^{0,48} P_{o}^{-1,04}\right)\right\rfloor \times 10^{(A-V) / 10}
$$

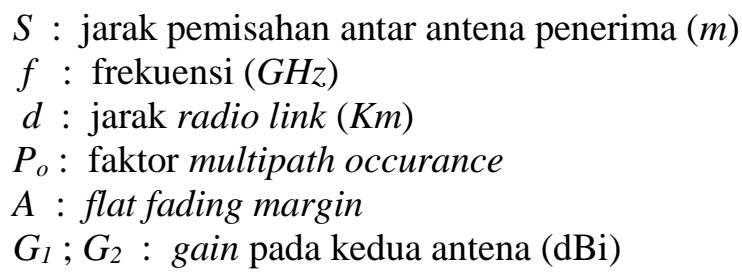

$$
\begin{aligned}
& I_{n s}=\left\lfloor 1-\exp \left(-3,34 \times 10^{-4} 10^{0,87} 5^{-0,12} 55,85^{0,48} 29,588^{-1,04}\right)\right\rfloor \times 10^{(64,53-0) / 10} \\
& I_{n s}=3,38844
\end{aligned}
$$

- Perhitungan Kuadrat Koefisien Korelasi Non-selective

$$
K_{n s}^{2}=1-\frac{I_{n s} x P_{n s}}{\eta}
$$

dimana:

$$
\begin{gathered}
I_{n s}: \text { improvement factor } \\
P_{n s}: \text { probabilitas outage non-selective } \\
\eta \quad: \text { parameter multipath activity }
\end{gathered}
$$

$$
\begin{aligned}
& K_{n s}, S^{2}=1-\frac{I_{n s} x P_{n s}}{\eta} \\
& K_{n s}, S^{2}=1-\frac{3,38844 x 0,000010426}{0,921} \\
& K_{n s}, S^{2}=0.9999617
\end{aligned}
$$

- Perhitungan Koefisien Korelasi Relative Amplitude

$$
\begin{aligned}
& r_{w}=1-0,6921\left(1-K_{n s}, S^{2}\right)^{1.034}, \text { untuk } K_{n s} S^{2} \geq 0.26 \\
& r_{w}=1-0,6921(1-0,9999617)^{1.034} \\
& r_{w}=0,9999892751
\end{aligned}
$$

- Perhitungan Kuadrat Koefisien Selective

$$
\begin{aligned}
& K_{s}{ }^{2}=1-0,3957\left(1-r_{w}\right)^{0,5136} \\
& K_{s}{ }^{2}=1-0,3957(1-0,9999892751)^{0,5136} \\
& K_{s}{ }^{2}=0,9988908864
\end{aligned}
$$

- Perhitungan Probabilitas Outage Non-Selective

$$
\begin{aligned}
& P_{d n s}=\frac{P_{n s}}{I_{n s}} \\
& P_{d n s}=\frac{0,000010426}{3,38844} \\
& P_{d n s}=0,0000030769321
\end{aligned}
$$

- Perhitungan Mean Time Delay

$$
\begin{aligned}
\tau_{m} & =0,7\left(\frac{d}{50}\right)^{1,3} \\
\tau_{m} & =0,7\left(\frac{55,85}{50}\right)^{1,3} \\
\tau_{m} & =0,8082899241 n s
\end{aligned}
$$


- Perhitungan Probabilitas Outage Selective

$$
\begin{aligned}
P_{d s} & =\frac{P_{s}^{2}}{\eta\left(1-K_{s}^{2}\right)} \\
P_{d s} & =\frac{0,0027896^{2}}{0,921(1-0,9988908864)} \\
P_{d s} & =0,0007654165235
\end{aligned}
$$

- Perhitungan Probabilitas Outage Total

$$
\begin{aligned}
& P_{d}=\left(P_{d n s}^{0,75}+P_{d s}^{0,75}\right)^{1,33} \\
& P_{d}=\left(0,0000030769321^{0,75}+0,0007654165235^{0,75}\right)^{1,33} \\
& P_{d}=0,000795860116
\end{aligned}
$$

- Perhitungan Availability

$$
\begin{aligned}
& A v=1-P_{d} \\
& A v=1-0,000795860116 \\
& A v=0,9992641399
\end{aligned}
$$

\begin{tabular}{|c|c|c|c|}
\hline & Satuan & Simpang Lubuk & Pulau Pongok \\
\hline Elevation & $(m)$ & 11 & 67 \\
\hline Latitude & & $1063936.40 \mathrm{E}$ & $1070245.00 \mathrm{E}$ \\
\hline Longitude & & $023332.10 \mathrm{~S}$ & $025245.99 \mathrm{~S}$ \\
\hline True Azimuth & ()$\left.^{o}\right)$ & 129,58 & 309,56 \\
\hline Antenna height & $(m)$ & 115 & 60 \\
\hline Antenna Gain & $(d B i)$ & \multicolumn{2}{|c|}{44,62} \\
\hline Frequency & $(\mathrm{MHz})$ & \multicolumn{2}{|c|}{5000} \\
\hline Polarization & & \multicolumn{2}{|c|}{ Horizontal } \\
\hline Path length & $(\mathrm{Km})$ & \multicolumn{2}{|c|}{55,85} \\
\hline Free space loss & $(d B)$ & \multicolumn{2}{|c|}{141,36} \\
\hline Atmospheric loss & $(d B)$ & \multicolumn{2}{|c|}{2,92} \\
\hline TX power & (watt) & \multicolumn{2}{|c|}{31,6} \\
\hline TX power & $(d B m)$ & \multicolumn{2}{|c|}{45} \\
\hline EIRP & $(d B m)$ & \multicolumn{2}{|c|}{89,62} \\
\hline RX threshold criteria & & \multicolumn{2}{|c|}{ BER $10^{-6}$} \\
\hline RX thershold level & $(d B m)$ & \multicolumn{2}{|c|}{$-74,6$} \\
\hline RX signal & $(\mathrm{dBm})$ & \multicolumn{2}{|c|}{$-10,07$} \\
\hline Geoclimatic factor & & \multicolumn{2}{|c|}{0,000372054} \\
\hline Occurance factor & & \multicolumn{2}{|c|}{29,588} \\
\hline Rain Rate & $(\mathrm{mm} / \mathrm{hr})$ & \multicolumn{2}{|c|}{145} \\
\hline Rain Attenuation & $(d B)$ & \multicolumn{2}{|c|}{2,15} \\
\hline Flat Fade Margin & $(d B)$ & \multicolumn{2}{|c|}{64,53} \\
\hline Path inclination & (mrad) & \multicolumn{2}{|c|}{0,0179} \\
\hline
\end{tabular}

TABEL Hasil Analisa Perhitungan Tanpa Menggunakan Diversitas

\begin{tabular}{|l|l|}
\hline Probabilitas Outage Total & 0,002800 \\
\hline Availability & 0,997199 \\
\hline ITU-R Outage Objective & 0,000448 \\
\hline ITU-R Availability & 0,999252 \\
\hline
\end{tabular}

TABEL Hasil Analisa Perhitungan Menggunakan Teknik Diversitas

\begin{tabular}{|l|l|}
\hline Probabilitas Outage Total & 0,000795 \\
\hline Availability & 0,999264 \\
\hline ITU-R Outage Objective & 0,000448 \\
\hline ITU-R Availability & 0,999252 \\
\hline
\end{tabular}

TABEL Microwave Worksheet Simpang Lubuk - Pulau Pongok $5 \mathrm{GHz}$

Berdasarkan hasil perhitungan di atas, harga probabilitas outage total dan availability sistem radio link Simpang Lubuk - Pulau Pongok harus menggunakan teknik diversitas agar memenuhi batas yang di rekomendasikan oleh ITU-R. berarti link Simpang Lubuk - Pulau Pongok ini layak untuk di implementasikan menjadi backbone link. 


\section{Radio Link Pulau Pongok - Pulau Nasik}

TABEL Hasil Analisa Perhitungan Tanpa Menggunakan Diversitas

\begin{tabular}{|l|l|}
\hline Probabilitas Outage Total & 0,000808 \\
\hline Availability & 0,999191 \\
\hline ITU-R Outage Objective & 0.000448 \\
\hline ITU-R Availability & 0.999252 \\
\hline
\end{tabular}

TABEL Hasil Analisa Perhitungan Menggunakan Teknik Diversitas

\begin{tabular}{|l|l|}
\hline Probabilitas Outage Total & 0,000353 \\
\hline Availability & 0.999646 \\
\hline ITU-R Outage Objective & 0.000448 \\
\hline ITU-R Availability & 0.999252 \\
\hline
\end{tabular}

TABEL Microwave Worksheet Pulau Pongok - Pulau Nasik 5GHz

\begin{tabular}{|c|c|c|c|}
\hline & Satuan & Pulau Pongok & Pulau Nasik \\
\hline Elevation & $(m)$ & 11 & 67 \\
\hline Latitude & & $02^{\circ} 52^{\prime} 45.99^{\prime \prime} \mathrm{S}$ & $02^{\circ} 44^{\prime} 11.00^{\prime \prime} \mathrm{S}$ \\
\hline Longitude & & $107^{\circ} 02^{\prime} 45.00^{\prime \prime} \mathrm{E}$ & $107^{\circ} 39^{\prime} 25.00^{\prime \prime} \mathrm{E}$ \\
\hline True Azimuth & $\left({ }^{o}\right)$ & 84,51 & 264,49 \\
\hline Antenna height & $(m)$ & 75 & 70 \\
\hline Antenna Gain & $(d B i)$ & \multicolumn{2}{|c|}{$\frac{1}{44.62}$} \\
\hline Frequency & $(\mathrm{MHz})$ & \multicolumn{2}{|c|}{5000} \\
\hline Polarization & & \multicolumn{2}{|c|}{ Horizontal } \\
\hline Path length & $(K m)$ & \multicolumn{2}{|c|}{41,71} \\
\hline Free space loss & $(d B)$ & \multicolumn{2}{|c|}{138,819} \\
\hline Atmospheric loss & $(d B)$ & \multicolumn{2}{|c|}{2} \\
\hline TX power & (watt) & \multicolumn{2}{|c|}{33} \\
\hline TX power & $(d B m)$ & \multicolumn{2}{|c|}{45} \\
\hline EIRP & $(d B m)$ & \multicolumn{2}{|c|}{89.62} \\
\hline RX thershold criteria & & \multicolumn{2}{|c|}{ BER $10^{-6}$} \\
\hline RX thershold level & $(d B m)$ & \multicolumn{2}{|c|}{-74.6} \\
\hline RX signal & $(d B m)$ & \multicolumn{2}{|c|}{$-7,789$} \\
\hline Geoclimatic factor & & \multicolumn{2}{|c|}{0.000372054} \\
\hline Occurance factor & & \multicolumn{2}{|c|}{9,932} \\
\hline Rain Rate & $(\mathrm{mm} / \mathrm{hr})$ & \multicolumn{2}{|c|}{145} \\
\hline Rain Attenuation & $(d B)$ & \multicolumn{2}{|c|}{2,15} \\
\hline Flat Fade Margin & $(d B)$ & \multicolumn{2}{|c|}{66,81} \\
\hline Path inclination & (mrad) & \multicolumn{2}{|c|}{0,0479} \\
\hline
\end{tabular}

\section{Radio Link Pulau Nasik - Tanjung Pandan}

TABEL Hasil Analisa Perhitungan Tanpa Menggunakan Diversitas

\begin{tabular}{|l|c|}
\hline Probabilitas Outage Total & 0,000569 \\
\hline Availability & 0,999430 \\
\hline ITU-R Outage Objective & 0.000448 \\
\hline ITU-R Availability & 0.999552 \\
\hline
\end{tabular}

TABEL Hasil Analisa Perhitungan Menggunakan Teknik Diversitas

\begin{tabular}{|l|l|}
\hline Probabilitas Outage Total & $0,0,0007$ \\
\hline Availability & 0.999289 \\
\hline ITU-R Outage Objective & 0.000448 \\
\hline ITU-R Availability & 0.999552 \\
\hline
\end{tabular}

Tabel Microwave Worksheet Pulau Nasik - Tanjung Pandan 5GHz

\begin{tabular}{|c|c|c|c|}
\hline & Satuan & Pulau Nasik & Tanjung Pandan \\
\hline Elevation & $(\mathrm{m})$ & 69 & 25 \\
\hline Latitude & & $02^{\circ} 50^{\prime} 35.90^{\prime \prime} \mathrm{S}$ & $02^{\circ} 44^{\prime} 11.00^{\prime \prime} \mathrm{S}$ \\
\hline Longitude & & $107^{\circ} 25^{\prime} 09.40^{\prime \prime} \mathrm{E}$ & $107^{\circ} 39^{\prime} 25.00^{\prime \prime} \mathrm{E}$ \\
\hline True Azimuth & $\left({ }^{\circ}\right)$ & 65,90 & 245,89 \\
\hline Antenna height & (m) & 50 & 90 \\
\hline Antenna Gain & $(\mathrm{dBi})$ & \multicolumn{2}{|c|}{$\frac{1}{44.62}$} \\
\hline Frequency & $(\mathrm{MHz})$ & \multicolumn{2}{|c|}{5000} \\
\hline Polarization & & \multicolumn{2}{|c|}{ Horizontal } \\
\hline Path length & $(\mathrm{Km})$ & \multicolumn{2}{|c|}{28,95} \\
\hline Free space loss & $(\mathrm{dB})$ & \multicolumn{2}{|c|}{135,65} \\
\hline Atmospheric loss & $(\mathrm{dB})$ & \multicolumn{2}{|c|}{1,51} \\
\hline TX power & (watt) & \multicolumn{2}{|c|}{2} \\
\hline TX power & $(\mathrm{dBm})$ & \multicolumn{2}{|c|}{33} \\
\hline
\end{tabular}




\begin{tabular}{|l|c|c|}
\hline EIRP & $(\mathrm{dBm})$ & 78,42 \\
\hline RX thershold criteria & & $\mathrm{BER} 10^{-6}$ \\
\hline RX thershold level & $(\mathrm{dBm})$ & -74.6 \\
\hline RX signal & $(\mathrm{dBm})$ & $-3,95$ \\
\hline Geoclimatic factor & & 0,000372054 \\
\hline Occurance factor & $(\mathrm{mm} / \mathrm{hr})$ & 2,4 \\
\hline Rain Rate & $(\mathrm{dB})$ & 145 \\
\hline Rain Attenuation & $(\mathrm{dB})$ & 1,72 \\
\hline Flat Fade Margin & $(\mathrm{mrad})$ & 70,65 \\
\hline Path inclination & & 0,13 \\
\hline
\end{tabular}

Berdasarkan hasil perhitungan di atas, harga probabilitas outage total dan availability sistem radio link Pulau Bangka - Pulau Belitung memenuhi batas yang di rekomendasikan oleh ITUR. sehingga link tersebut layak untuk di implementasikan menjadi backbone link.

\section{KESIMPULAN}

Berdasarkan apa yang telah ditulis dan menganalisa permasalahan, penulis memberikan kesimpulan sebagai berikut untuk menghubungkan Pulau Bangka - Pulau Belitung dibutuhkan 3 Hop.

\begin{tabular}{|c|l|c|c|c|c|}
\hline No. & \multicolumn{1}{|c|}{ Site A } & Site B & Pt & Av & Keterangan \\
\hline 1. & Simpang Lubuk & Pulau Pongok & 0,000795 & 0.999264 & LOS, menggunakan teknik diversitas \\
\hline 2. & Pulau Pongok & Pulau Nasik & 0,000353 & 0,999646 & LOS, menggunakan teknik diversitas \\
\hline 3. & Pulau Nasik & Tanjung Pandan & 0,00007 & 0.999289 & LOS, menggunakan teknik diversitas \\
\hline
\end{tabular}

Dalam penghitungan radio link harus memperhatikan parameter - parameter yang mempengaruhi radio link itu sendiri. FSL (free Space Loss), Redaman dan Obstacle daerah tersebut dan Gain antenna. Dengan hasil penghitungan power link budget, kita dapat mengetahui besarnya daya pancar yang diterima receiver dan loss propagation maximum.

\section{DAFTAR PUSTAKA}

[1] Bates, Regis J, Broadband Telecommunications Handbook, San Fransisco, 2002.

[2] ITU-T Recommendation, Reability and Availability of Analogue Cable Transmission, 2003.

[3] Roger L. Freeman. "Radio System Design for Telecommunication (1-100 Ghz)

[4] Roger L. Freeman. "Telecommunication Transmission Handbook, Edisi ke Empat.

[5] Rec. ITU-R P.530-8, "Propagation Data and Prediction Method Required for The Design of Terresterial LINE OF SIGHT System".

[6] Rec. ITU-R P. 453, The Radio Refractive Index: ITS Formula and Refractivity Data”.

[7] Rec. ITU-R P 634-3, Error Performance Objectives for Real Digital Radi-Relay Link Forming Part of High-Grade Circuit Within An Integrated Service Digital Network".

[8] Rec. ITU-R P. 676-3, “Attenuation by Atmospheric Gases".

[9] Rec. ITU-R F.1093, "Effect of Multipath Propagation On The Design And Operation Of Line Of Sight Digital Radio-Relay Systems". 